\title{
Fast Procedure for Characterization of Voltage Sag for Medium Voltage (MV) Distribution Network without Online Monitoring Using Fault and Regression Analyses
}

\author{
Chin Koon Loo", Mau Teng Au* \\ ${ }^{\#}$ College of Graduate Study, University Tenaga Nasional (UNITEN), 43000 Kajang, Selangor, Malaysia \\ E-mail: loochinkoon@icloud.com \\ *Institute of Power Engineering, University Tenaga Nasional (UNITEN), 43000 Kajang, Selangor, Malaysia \\ E-mail: mtau@uniten.edu.my
}

\begin{abstract}
Power Quality (PQ) Management undertaken by most utilities including TNB involves monitoring/online measurement, data processing \& analysis, reporting and customers' complaints management. The Malaysian regulator requires proactive communication and PQ disturbance report covering specific details such as percentage remaining voltage, duration, and cause of voltage sag/dip events to be shared with affected customers. The above-stipulated requirement can be easily met for substations/exposed areas with online PQ measurements, which capture voltage magnitude and duration that could be corroborated with tripping events. However, it is not practical to have online monitoring facilities as the majority of medium voltage (MV) substations are not equipped with voltage and current transformers where measurements could be tapped. Current procedures of characterizing voltage sag for substations without measurements facilities is time-consuming. In this paper, a fast procedure using combinations of fault simulations and regression analysis to characterize voltage sag is proposed. Extensive results from 160 simulation cases comprising 4 network operating configurations, 20 fault distances, and 2 fault types are used in the regression formulation. The results based on the proposed fast procedure for MV distribution network without online monitoring is found to be fairly accurate.
\end{abstract}

Keywords — voltage sag (dip) characteristic; fault analysis; regression analysis; voltage sag propagation

\section{INTRODUCTION}

Like many utilities, Malaysian integrated utility company TNB, has set up online Power Quality Monitoring System (PQMS) for the monitoring, data processing and diagnosis, and reporting of PQ events. The system has assisted in managing customers' complaints and meeting regulator's license condition for monthly and annual reports on power quality performance. The complete system encompasses Power Quality Recorder (PQR) installed at strategic substations for capturing both voltage and current of PQ events at MV $(33 \mathrm{kV}$ or $11 \mathrm{kV})$, and communication link and servers at specific locations. Since 2005, more than 158 monitoring points have been installed with permanent PQR throughout Peninsular Malaysia. The system uses a smart software which integrates signal processing and artificial intelligent techniques to diagnose recorded waveforms [1] [2] [3]. The system outputs, i) types of PQ disturbances such as voltage sag, swell, harmonics, transient and notches, ii) location of sources of voltage sags at upstream or downstream of the monitoring point, and iii) causes of voltage sags, due to permanent faults originating from utility network or customer's internal installation or non-permanent faults which is transient or incipient [3] [4].

The summary of the PQ disturbance analysis in text format is sent to distribution operation and maintenance engineers at branch offices via short messaging system (SMS) for sharing with the affected customers. This proactive communication helps to alleviate complaints and enable customers to restart tripped sensitive equipment/processes. Reference [5] highlights the threshold voltage at which equipment may trip or stop working; such as a starter coil that drop out at 0.6 per-unit (p.u.) voltage, or a variable-frequency drive that trip at 0.8 to 0.85 p.u. voltage. Several measures for surviving voltage sag or provide ride through capability were recommended, which include uninterruptible power supply (UPS), high breakdown torque for induction motors, higher withstand voltages for control systems, variable-frequency drives, etc. The implementation of such mitigation solutions whether partial or for the whole plant, depends very much on business investment decisions. 
Often, customers particularly in the electronic and semiconductor industry expect the utility company to reduce the number of voltage sag incidents per year.

Besides a proactive engagement with the affected commercial and industrial customers during the occurrence of a voltage sag event, a standardized PQ report is generated from PQMS Web based application (developed to compile all PQ data, register complaints and generate reports) and shared with the affected customers. Key details include time and date of the event, percentage remaining voltage and duration, cause of voltage sag, and action plan. The report is then submitted as required by the regulator in compliance with the service level agreement.

Since not all substations are equiped with permanent online $\mathrm{PQR}$, it has been very challenging to communicate with the affected customers and meet the timeframe required for the $\mathrm{PQ}$ report to address the customers complaints. The existing procedure for characterizing voltage sag for non-monitoring sites involves several steps, which are, i) send protection team to check relay operation from suspected substation and download fault current data from relay, ii) use the fault current data to calculate relay operating time, iii) calculate voltage sag duration, which is the relay operating time plus circuit breaker operating time, iv) verify type of fault and fault distance from the source, v) draw the simplied diagram of faulted network, vii) calculate source impedance and fault impedance, and vii) calculate magnitude of the remaining voltage using equations (1). The procedure is tedious and time consuming.

Based on literatures, for lack of measurement networks, the characteristics of voltage sag can be derived from single measurement point as recommended by [6] using a procedure based on symmetrical components at the identified fault pointed. The procedure however requires operation and maintainance engineers at branch offices to handle several parameters and variables which is challenging, tedious and time consuming. Sazali et al [7] used patterns captured by digital fault recorder and fault signature analysis to formulate equations for different types of faults i.e. lightning, tree encroachment and equipment failure in transmission systems. The information from fault signature analysis is useful for transmission system operator to decide the next course of actions in an easier and faster manner. The formulation of pattern obtained from fault analysis is relevant as it is not prudent utility practice to install digital disturbance recorder at every substation.

In 2012, Kamble et al [8] performed a case study using fault simulations for 3-phase, phase-to-phase, 2-phase to ground types of fault on an $11 \mathrm{kV}$ distribution system with source of supply from $33 / 11 \mathrm{kV}$ transformers and compare the results with online monitoring for classification of voltage sags in distribution systems due to short circuit faults. However, no formulation was provided for non-monitoring sites. This paper proposes a fast procedure for characterization of voltage sag for MV distribution network without online monitoring by using fault and regression analyses to derive plots of remaining voltage magnitude and fault current versus fault distance for various network configurations and fault types. The procedure involves 3 steps i.e. i) verify the fault distance from the source, ii) obtain the remaining voltage magnitude from the plot/formula, and iii) obtain fault current from plot/formula and calculate relay operating time and duration of voltage sag. Section II shows the material and method while section III presents the results and discussion. Validation of simulation results and conclusion is provided in Section IV.

\section{MATERIAL AND METHOD}

\section{A. Radial System}

Based on circuit theory for radial systems and symmetrical fault, the magnitude of voltage sag at the point of common coupling (PCC) during a short circuit can be calculated using basic impedance divider as shown in Fig. 1 and equation (1) with the assumption that all load currents be neglected [9] [10] [11] [12].

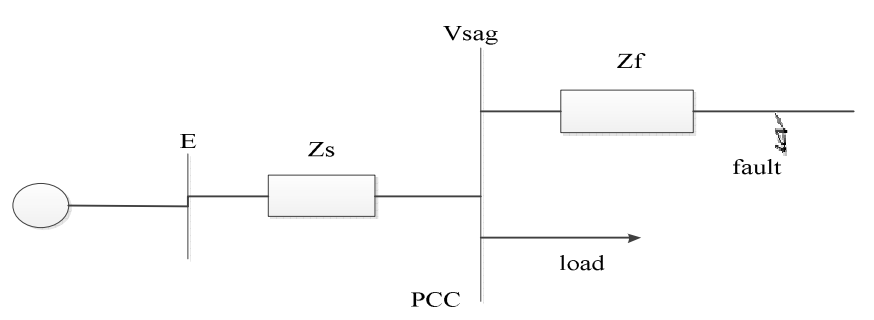

Fig. 1. Voltage sag using impedance divider

$$
V_{s a g}=\frac{z_{f}}{\left(z_{g}+z_{f}\right)} E
$$

Where, $E$ is the prefault voltage and is usually approximated as 1 per unit.

Assuming the feeder has an impedance of $z$ ohm per $\mathrm{km}$ and the distance between the substation and the fault is $l$, then $\mathrm{Z}_{\mathrm{f}}=\mathrm{z} l$

$$
V_{s a g}=\frac{z l}{\left(z_{s}+z l\right)}
$$

The distance $l$ is derived as:

$$
l=\frac{z_{g}}{g} \times \frac{V_{\operatorname{sag}}}{1-V_{g a g}}
$$

The fault current $\mathrm{I}_{\mathrm{f}}$ is given as,

$$
I_{f}=\frac{E}{\left(Z_{s}+a l\right)}
$$

\section{B. Meshed system}

For a typical n-bus power system as shown in Fig. 2 and assuming balance operating condition, a per-phase circuit model can be used [13]. Each generator/transmission grid is represented by a constant voltage source behind appropriate machine/source reactance. Each transformer is represented by its reactance while transmission lines are represented by their equivalent $\pi$-model. All impedances are expressed in per unit on a common MVA base, i.e. 100 MVA. 


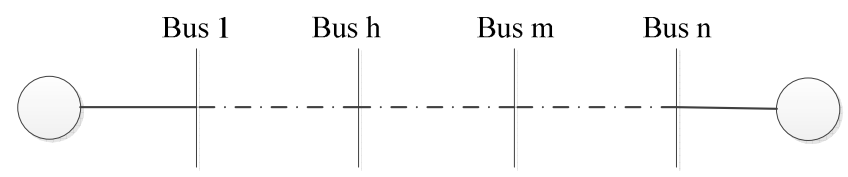

Fig. 2. Typical n-bus power system

The pre-fault bus voltages are obtained from the load flow solutions and are given by the column vector $\mathrm{V}_{\text {bus }}(0)$ in equation (5),

$$
V_{w s}(0)=\left(\begin{array}{c}
V_{1}(0) \\
\vdots \\
V_{h}(0) \\
\vdots \\
V_{m}(0) \\
\vdots \\
V_{n}(0)
\end{array}\right)
$$

During fault, short circuit currents are higher than the load currents. As such load currents are ignored. Using Thevenin's theorem, when a balanced three-phase fault is applied at bus ' $\mathrm{m}$ ' through a fault impedance $\mathrm{Z}_{\mathrm{f}}$, the changes in the network voltages given by $\Delta \mathrm{V}$ is equivalent to the one caused by adding voltage $\mathrm{V}_{\mathrm{m}}(0)$, with all other sources short circuited as in Fig. 3 [12].

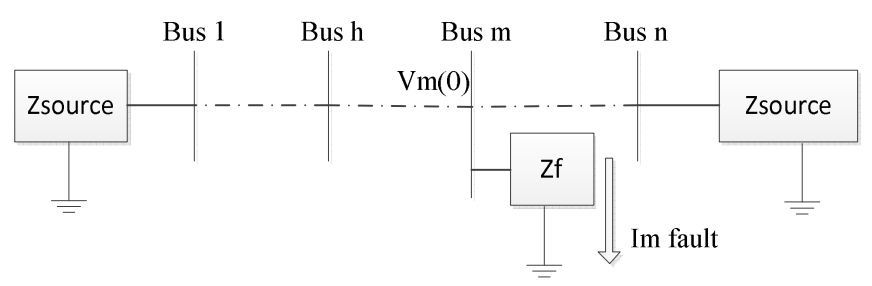

Fig. 3. Typical n-bus power system during fault.

Hence, the network bus voltage changes will be as follows,

$$
\Delta V_{b u s}=\left(\begin{array}{c}
\Delta V_{1} \\
\vdots \\
\Delta V_{n} \\
\vdots \\
\Delta V_{m} \\
\vdots \\
\Delta V_{n}
\end{array}\right)
$$

Using superposition of the pre-fault bus voltages and the changes in the bus voltages, the bus voltages during fault are obtained as,

$$
V_{\text {ws }}(F)=V_{\text {ou }}(0)+\Delta V_{\text {bu }}
$$

In the Thevenin's circuit of Fig 3, current entering every bus is zero except at the faulted bus ' $m$ ', where the fault current is leaving the bus and therefore it is considered as a negative current entering the bus ' $m$ '. For a load flow calculation, the node voltage equation for n-bus network is given by:

$$
I_{\text {bus }}=Y_{\text {bus }} V_{\text {bus }}
$$

Where $I_{b u s}$ is the bus current vector entering the faulted bus and $Y_{b u s}$ is the bus admittance matrix. $V_{b u s}$ is the bus voltage vector giving the voltages of all buses. Bus current vector $I_{b u s}$ actually represents the current source of the n-bus network, replacing the voltage source. During symmetrical fault at bus ' $\mathrm{m}$ ', the nodal equation becomes,

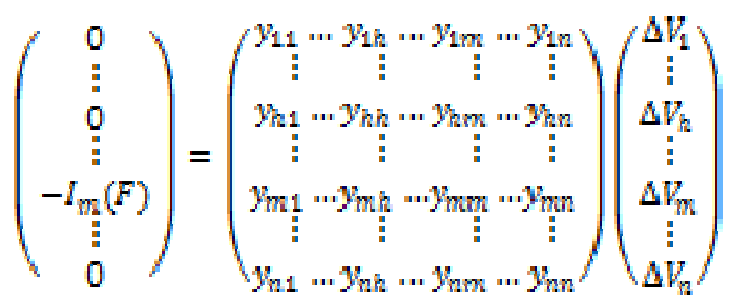

Or

$$
I_{\text {bus }}(\boldsymbol{F})=Y_{\text {bus }} \Delta V_{\text {sus }}
$$

Solving for $\Delta V_{b u s}$, we obtain,

$$
\Delta V_{\text {bus }}=Z_{\text {bus }} I_{\text {bus }}(F)
$$

Where $Z_{\text {bus }}$ is known as the bus impedance matrix and is obtained by inverting the $Y_{\text {bus. }}$ Writing equation (7) in terms of its matrix elements,

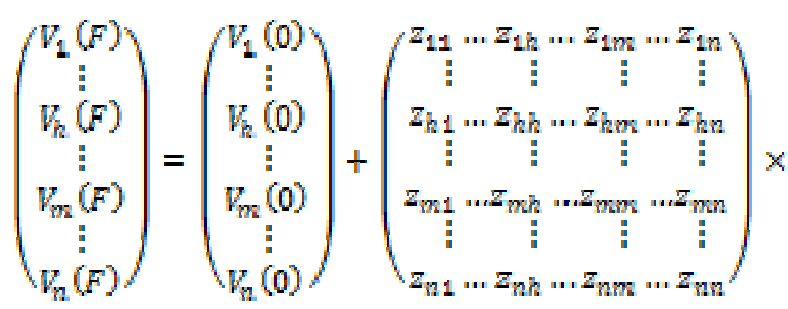

$\left(\begin{array}{c}0 \\ \vdots \\ 0 \\ \vdots \\ -Z_{m}(F) \\ \vdots \\ 0\end{array}\right)$

Looking at the $\mathrm{m}^{\text {th }}$ row with non-zero element in the current vector, the relation becomes,

Also,

$$
V_{m}(F)=V_{m}(0)-z_{m m} Z_{m}(F)
$$

$$
V_{\mathrm{m}}(F)=z_{f} I_{\mathrm{m}}(F)
$$

Combining these two equations yields,

$$
I_{m}(F)=\frac{v_{m}(0)}{s_{m m}+s_{f}}
$$

Therefore, for a fault at bus ' $\mathrm{m}$ ', only element $\mathrm{z}_{\mathrm{mm}}$ from $Z_{b u s}$ is needed, which is the Thevenin's impedance as viewed from the bus ' $m$ ' into the network under study. For bolted fault, $z_{f}$ is zero and the relation is reduced to,

$$
I_{m}(F)=\frac{I_{m}(0)}{I_{m m}}
$$


For the $\mathrm{h}^{\text {th }}$ row, the voltage during fault can be expressed as,

$$
V_{h}(F)=V_{h}(0)-Z_{h m} I_{m}(F)
$$

Subsitute for $I_{n}(F)$ derives,

$$
V_{h}(F)=V_{h}(0)-\frac{z_{h m}}{z_{m m}+z_{f}} V_{m}(0)
$$

As such, equation (17) can be used to calculate the voltage of the monitored bus ' $h$ ' or the voltage sag at bus ' $h$ ' due to a fault on any bus ' $m$ ' of the system under study. In order to do this, the $Z_{b u s}$ of the system need to be constructed and the prefault voltage of both bus $h$ and $m$ must be known. In this paper, DIgSILENT Power Factory commercial software is used as the simulation tool for load flow and fault analysis of 3-phase and phase-to-phase faults. Single phase to ground (SLG) is excluded as TNB practise neutral earthing resistance (NER) grounding method to limit the earth fault current at full load current of the single power transformer. Such method of grounding the star point does not lead to voltage sag propagation to utilization level for SLG fault [14] [15].

\section{Fault Simulations and Regression Analysis}

Fault simulations and sensitivity analysis by varying the fault distance from PCC were performed using DIgSILENT Power Factory software on a meshed power system with typical transmission and distribution system configurations.

Two cases of network configurations are considered in this study.

- Case I: 2x30 MVA 132/11kV Transformer,

- $\quad$ Case II: 2x90 MVA 132/33kV Transformer, and 2x30 MVA 33/11kV Transformer.

The network parameters used in simulating the network configuration are as shown in Table 1 [12].

TABLE I

NETWORK COMPONENTS AND PARAMETERS.

\begin{tabular}{|c|l|l|}
\hline No & $\begin{array}{l}\text { Components and } \\
\text { Description }\end{array}$ & Network Parameters \\
\hline 1 & Grid Source $(132 \mathrm{kV})$ & 4600 MVA 3-phase \\
\hline 2 & $\begin{array}{l}132 / 33 \mathrm{kV} \text { Transformer } \\
\text { Impedance }\end{array}$ & $13 \%$ \\
\hline 3 & $\begin{array}{l}132 / 11 \mathrm{kV} \text { Transformer } \\
\text { Impedance }\end{array}$ & $13 \%$ \\
\hline 4 & $\begin{array}{l}33 / 11 \mathrm{kV} \text { Transformer } \\
\text { Impedance }\end{array}$ & $10 \%$ \\
\hline 5 & $\begin{array}{l}11 \mathrm{kV} \text { underground cable } \\
\text { XLPE } 240 \text { sq mm } 3 \text { core } \\
\text { Al (ohm/km) }\end{array}$ & $\begin{array}{l}\mathrm{R}_{1}=0.1293 ; \mathrm{R}_{0}=1.0518 \\
\mathrm{X}_{1}=0.0889 ; \mathrm{X}_{0}=1.2\end{array}$ \\
\hline 6 & Base MVA & $100 \mathrm{MVA}$ \\
\hline
\end{tabular}

For both cases I and II, three-phase and phase-to-phase faults were applied at various fault points under two (2) different operating conditions, i) $11 \mathrm{kV}$ bus-section "OPEN", and ii) $11 \mathrm{kV}$ Bus-section "CLOSE".

Simulation results obtained for fault current and remaining voltage at various buses are tabulated and plotted on dual-axis graphs of remaining voltage in per unit and fault current in $\mathrm{kA}$ as a function of fault distance.

1) Case I: $2 \times 30$ MVA $132 / 11 \mathrm{kV}$ transformer with bus section 'OPEN' and 'CLOSE' operational conditions. See Fig. 4.

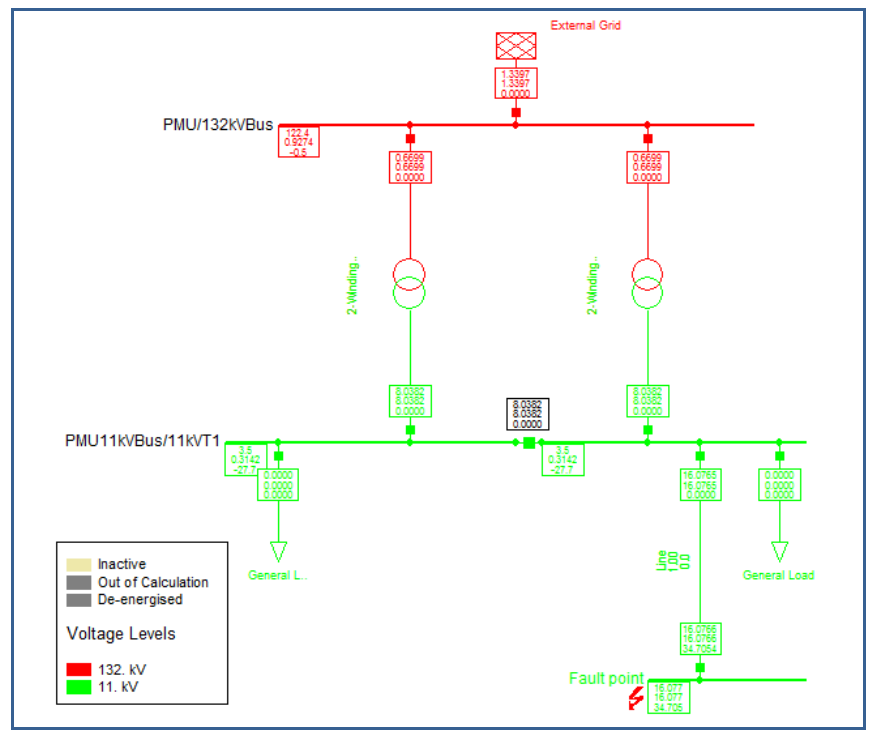

Fig. 4. Case I- Model of 2x30 MVA 132/11 kV developed using DigSilent Power Factory.

TABLE II

FAULT DISTANCE FROM PCC, REMAINING VOLTAGE AND FAULT CURRENT FOR CASE I.

\begin{tabular}{|c|c|c|c|c|}
\hline $\mathrm{d}(\mathrm{km})$ & $\begin{array}{c}\text { Vsag }(\mathrm{pu}) \\
1 T x\end{array}$ & $\begin{array}{c}\text { Vsag (pu) } \\
2 \mathrm{Txs}\end{array}$ & $\begin{array}{c}\text { If(kA) } \\
1 \mathrm{Tx}\end{array}$ & If(kA) 2Txs \\
\hline 0.0 & 0.000 & 0.000 & 11.482 & 21.828 \\
\hline 0.2 & 0.055 & 0.101 & 11.105 & 20.465 \\
\hline 0.4 & 0.106 & 0.189 & 10.732 & 19.155 \\
\hline 0.6 & 0.154 & 0.266 & 10.367 & 17.926 \\
\hline 0.8 & 0.198 & 0.332 & 10.012 & 16.790 \\
\hline 1.0 & 0.239 & 0.389 & 9.677 & 15.766 \\
\hline 1.5 & 0.329 & 0.502 & 8.880 & 13.555 \\
\hline 2.0 & 0.404 & 0.584 & 8.167 & 11.811 \\
\hline 2.5 & 0.466 & 0.644 & 7.537 & 10.427 \\
\hline 3.0 & 0.517 & 0.690 & 6.980 & 9.311 \\
\hline 3.5 & 0.561 & 0.726 & 6.489 & 8.400 \\
\hline 4.0 & 0.598 & 0.755 & 6.055 & 7.643 \\
\hline 4.5 & 0.630 & 0.779 & 5.669 & 7.007 \\
\hline 5.0 & 0.658 & 0.799 & 5.326 & 6.465 \\
\hline 5.5 & 0.682 & 0.815 & 5.019 & 6.000 \\
\hline 6.0 & 0.703 & 0.829 & 4.743 & 5.594 \\
\hline 6.5 & 0.722 & 0.842 & 4.495 & 5.240 \\
\hline 7.0 & 0.738 & 0.852 & 4.270 & 4.927 \\
\hline 7.5 & 0.753 & 0.861 & 4.065 & 4.648 \\
\hline 8.0 & 0.767 & 0.870 & 3.878 & 4.399 \\
\hline 8.5 & 0.779 & 0.877 & 3.707 & 4.175 \\
\hline 9 & 0.790 & 0.884 & 3.550 & 3.973 \\
\hline & & & & \\
\hline
\end{tabular}

Table 2 summarized the the remaining voltage and fault curent recorded for each fault distance from fault simulations for Case I.

The dual-axis graphs of fault current $\left(\mathrm{I}_{\mathrm{f}}\right)$ and remaining voltage $\left(\mathrm{V}_{\mathrm{sag}}\right)$ versus fault distance plotted for $11 \mathrm{kV}$ bussection "OPEN", and "CLOSE" are shown in Fig. 5. 


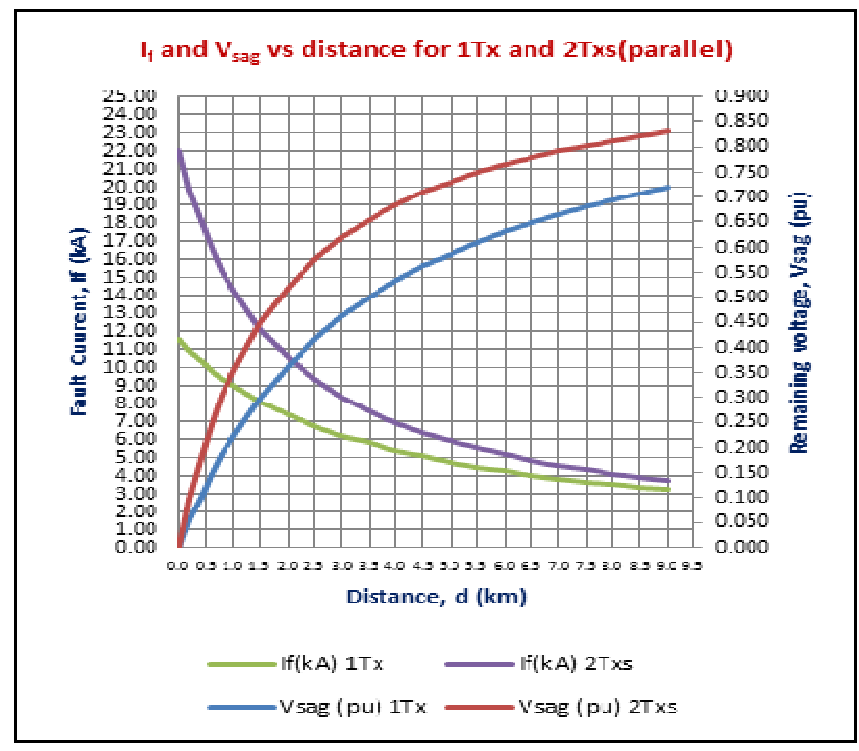

Fig 5. Graph of fault current and remaining voltage vs distance for Case I.

2) Case II: $2 \times 90$ MVA $132 / 33 \mathrm{kV}$ transformer and $2 \times 30$ MVA $33 / 11 \mathrm{kV}$ transformer with $11 \mathrm{kV}$ bus section 'OPEN' and 'CLOSE' operational conditions. See Fig. 6.

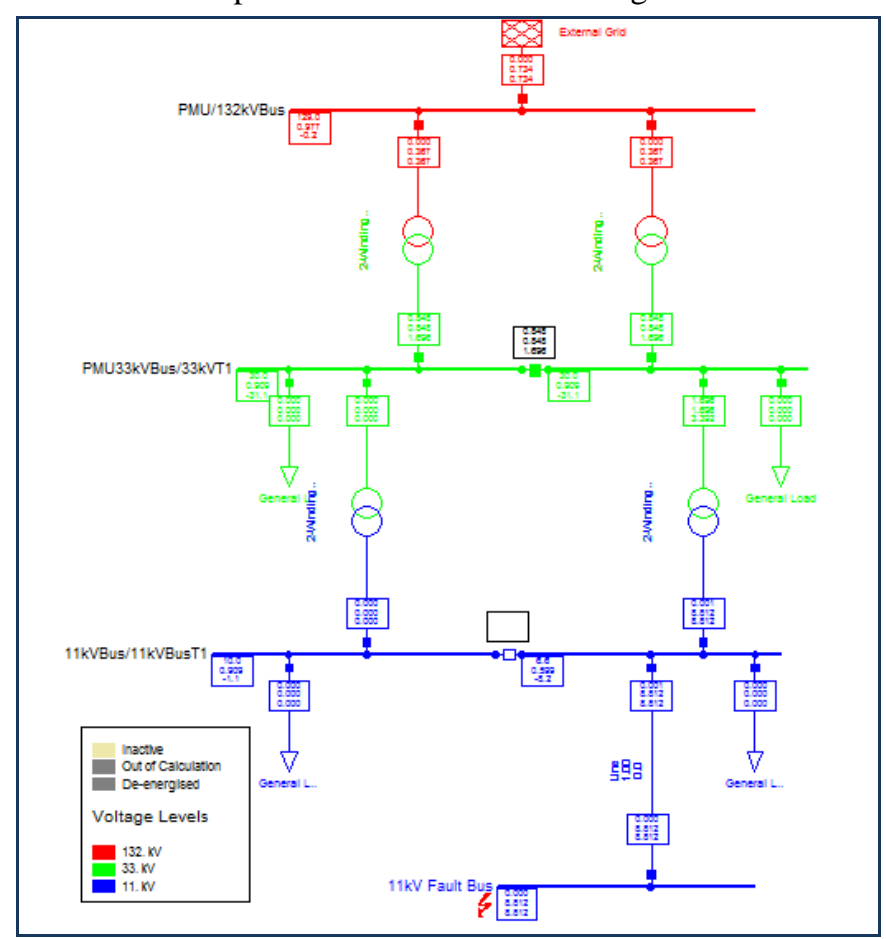

Fig. 6. Model of 2x90 MVA 132/33kV and 2x30 MVA 33/11kV

TABLE III

FAULT DISTANCE FROM PCC, REMAINING VOLTAGE AND FAULT CURRENT FOR CASE II.

\begin{tabular}{|c|c|c|c|c|c|}
\hline $\mathrm{d}(\mathrm{km})$ & $\begin{array}{c}\text { 1Tx PPU } \\
\text { Vsag11k } \\
\mathrm{V}\end{array}$ & $\begin{array}{c}\text { 1Tx } \\
\text { PMU } \\
\text { Vsag33k } \\
\mathrm{V}\end{array}$ & $\begin{array}{c}2 \mathrm{Tx} \\
\text { PPU } \\
\text { Vsag11 } \\
\mathrm{kV}\end{array}$ & $\begin{array}{c}2 \mathrm{Tx} \\
\text { PMU } \\
\text { Vsag33 } \\
\mathrm{kV}\end{array}$ & $\begin{array}{c}\text { If 1Tx } \\
\text { PPU(PMU) }\end{array}$ \\
\hline 0.0 & 0.000 & 0.780 & 0.000 & 0.639 & 12.280 \\
\hline 0.2 & 0.059 & 0.787 & 0.094 & 0.660 & 11.845 \\
\hline 0.4 & 0.113 & 0.795 & 0.176 & 0.682 & 11.415 \\
\hline 0.6 & 0.163 & 0.803 & 0.248 & 0.705 & 10.997 \\
\hline 0.8 & 0.209 & 0.810 & 0.311 & 0.726 & 10.593 \\
\hline 1.0 & 0.252 & 0.819 & 0.367 & 0.745 & 10.204 \\
\hline
\end{tabular}

\begin{tabular}{|l|l|l|l|l|l|}
\hline 1.5 & 0.345 & 0.838 & 0.477 & 0.787 & 9.305 \\
\hline 2.0 & 0.421 & 0.855 & 0.558 & 0.819 & 8.513 \\
\hline 2.5 & 0.483 & 0.869 & 0.620 & 0.844 & 7.820 \\
\hline 3.0 & 0.535 & 0.882 & 0.667 & 0.864 & 7.214 \\
\hline 3.5 & 0.578 & 0.892 & 0.705 & 0.879 & 6.685 \\
\hline 4.0 & 0.615 & 0.902 & 0.735 & 0.892 & 6.220 \\
\hline 4.5 & 0.646 & 0.910 & 0.760 & 0.902 & 5.810 \\
\hline 5.0 & 0.673 & 0.916 & 0.781 & 0.911 & 5.447 \\
\hline 5.5 & 0.696 & 0.923 & 0.798 & 0.918 & 5.124 \\
\hline 6.0 & 0.717 & 0.928 & 0.813 & 0.925 & 4.835 \\
\hline 6.5 & 0.735 & 0.932 & 0.827 & 0.930 & 4.575 \\
\hline 7.0 & 0.751 & 0.937 & 0.838 & 0.935 & 4.341 \\
\hline 7.5 & 0.765 & 0.940 & 0.848 & 0.939 & 4.128 \\
\hline 8.0 & 0.778 & 0.944 & 0.857 & 0.943 & 3.958 \\
\hline 8.5 & 0.789 & 0.947 & 0.865 & 0.946 & 3.758 \\
\hline 9 & 0.800 & 0.949 & 0.872 & 0.949 & 3.596 \\
\hline
\end{tabular}

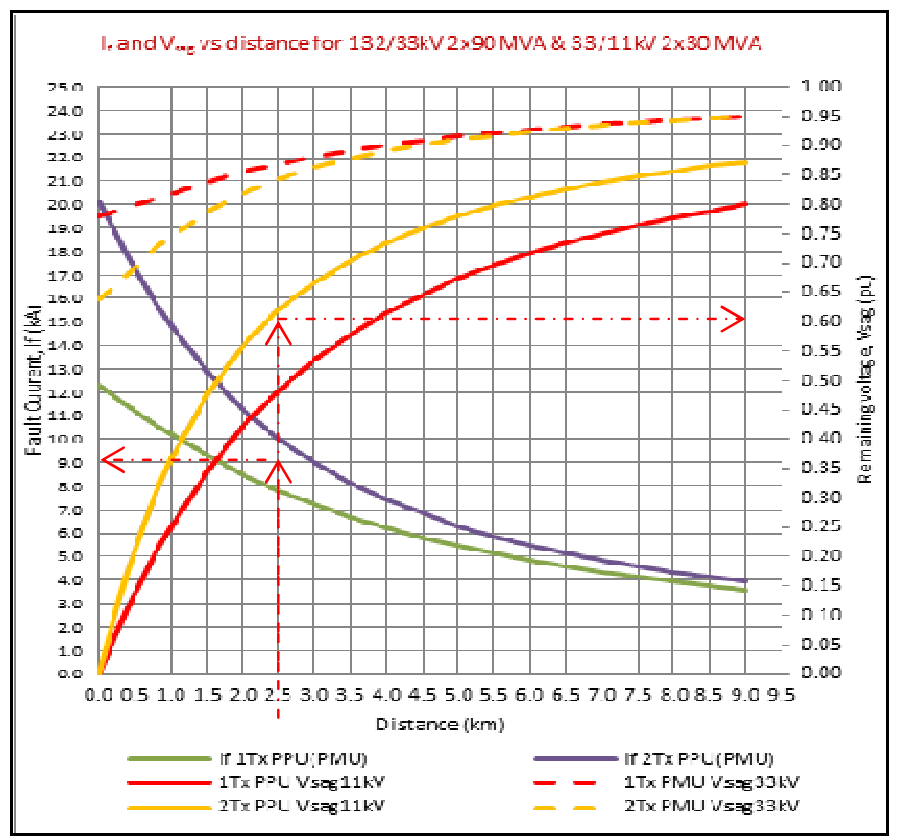

Fig. 7. Graph of fault current and remaining voltage vs distance for Case II.

The results obtained for Case II are summarized in Table 3 and graphed in Fig. 7.

The graphical representation of both fault current and remaining voltage versus fault distance provides clear visual guide to operation and maintenance engineers at branch offices to obtain information on fault current and remaining voltage of an impactful fault event causing voltage sag when the distance of fault from PCC is known. By projecting upwards from the horizontal distance axis, both remaining voltage and fault current of the particular fault distance can be obtained from the primary and secondary vertical axes. As an example, for a fault distance of $2.5 \mathrm{~km}$, the remaining voltage is $0.65(\mathrm{pu})$ and fault current is $10 \mathrm{kA}$ under $11 \mathrm{kV}$ bus-section "CLOSE" configuration.

The duration of the voltage sag event can then be easily obtain from the formula for relay operating time (for typical Standard Inverse definite minimum time relay) involving fault current as shown in equation (19).

$$
\text { Relay operating time }(s)=\frac{0.14}{\left(l_{T}{ }^{2.02}-1\right)} \times \text { TMS }
$$

Where, 
$I_{T}=\frac{l_{f}}{l_{z}}$,

\section{If Fault current (A)}

\section{Is: Relay Pickup current setting(A)}

TMS: Time Multiplier Setting

Assuming that breaker operating time is $50 \mathrm{~ms}$, then the duration of voltage sag is relay operating time plus breaker operating time. As such the full characteristic of a voltage sag i.e. magnitude and duration can easily be derived from the dual-axis graph developed from fault simulations.

On top of the visual dual-axes graphs, formulation of the curves is done using regression [16] analysis. A summary of the formulas derived are shown in Table 4 for 3-phase fault of $132 / 11 \mathrm{kV} 2 \times 30$ MVA configuration and Table 5 for 3phase fault of 132/3/11 kV 2x90/2x30 MVA configuration. The formulas for 2-phase faults and other network configurations can be derived using similar method.

Key variable that must be known for using the formulas is the fault distance $x$ in the formulation. By knowing the fault distance and type of $11 \mathrm{kV}$ cable, remaining voltage magnitude and duration can be quickly derived for areas without online monitoring. PQ report can be completed on time without delay and having to send protection personnel to download relay data which is a time consuming effort.

TABLE IV

DERIVED EQUATIONS FOR CASE I CONFIGURATION WITH 3-PHASE FAULT AT $11 \mathrm{KV}$ FEEDER.

\begin{tabular}{|c|c|}
\hline \multicolumn{2}{|c|}{ Network configuration: Bus-Section "OPEN" } \\
\hline Voltage/Fault Current & Derived Equations \\
\hline Remaining Voltage (p.u) & $\begin{array}{l}1.094 \times 10^{-5} x^{5}-3.992 \times 10^{-4} x^{4}+6.161 \times 10^{-} \\
{ }^{3} x^{3}-5.318 \times 10^{-2} x^{2}+2.866 \times 10^{-1} x- \\
2.367 \times 10^{-4}\end{array}$ \\
\hline Fault Current (kA) & $\begin{array}{l}9.484 \times 10^{-5} x^{5}-1.976 \times 10^{-3} x^{4}+6.601 \times 10^{-} \\
{ }^{3} x^{3}+1.532 \times 10^{-1} x^{2}-1.977 \times 10^{-1} x+11.492\end{array}$ \\
\hline \multicolumn{2}{|c|}{ Network configuration: Bus-Section "CLOSE" } \\
\hline Voltage/Fault Current & Derived Equations \\
\hline Remaining Voltage (p.u) & $\begin{array}{l}8.460 \times 10^{-5} x^{5}-2.434 \times 10^{-3} x^{4}+2.762 \times 10^{-} \\
{ }^{2} x^{3}-1.560 \times 10^{-1} x^{2}+5.193 \times 10^{-1} x+ \\
3.441 \times 10^{-3}\end{array}$ \\
\hline Fault Current (kA) & $\begin{array}{l}-3.349 \times 10^{-4} x^{5}+1.269 \times 10^{-2} x^{4}-1.950 \times 10^{-} \\
{ }^{1} x^{3}+1.585 x^{2}-7.508 x+21.88\end{array}$ \\
\hline
\end{tabular}

TABLE V

DERIVED EQUATIONS FOR CASE II CONFIGURATION WITH 3-PHASE FAULT AT $11 \mathrm{KV}$ FEEDER.

\begin{tabular}{|l|l|}
\hline \multicolumn{2}{|l|}{ Network configuration: Bus-Section "OPEN" (Equations for 11kV) } \\
\hline Voltage/Fault Current & Derived Equations \\
\hline & $\begin{array}{l}1.505 \times 10^{-5} x^{5}-5.193 \times 10^{-4} x^{4}+7.532 \times 10^{-} \\
\text {Remaining Voltage (p.u) }\end{array}$ \\
& $\begin{array}{l}3 x^{3}-6.079 \times 10^{-2} x^{2}+3.057 \times 10^{-1} x+ \\
1.527 \times 10^{-5}\end{array}$ \\
\hline
\end{tabular}

\begin{tabular}{|c|c|}
\hline Fault Current (kA) & $\begin{array}{l}8.027 \times 10^{-5} x^{5}-1.485 \times 10^{-3} x^{4}-9.916 \times 10^{-} \\
{ }^{4} x^{3}+2.202 \times 10^{-1} x^{2}-2.311 x+12.29\end{array}$ \\
\hline \multicolumn{2}{|c|}{ Network configuration: Bus-Section "CLOSE" (Equations for $11 \mathrm{kV}$ ) } \\
\hline Voltage/Fault Current & Derived Equations \\
\hline Remaining Voltage (p.u) & $\begin{array}{l}6.982 \times 10^{-5} x^{5}-2.039 \times 10^{-3} x^{4}+2.364 \times 10^{-} \\
{ }^{2} x^{3}-1.414 \times 10^{-1} x^{2}+4.825 \times 10^{-1} x+ \\
2.742 \times 10^{-3}\end{array}$ \\
\hline Fault Current (kA) & $\begin{array}{l}-2.129 \times 10^{-4} x^{5}+8.859 \times 10^{-3} x^{4}-1.471 \times 10^{-} \\
{ }^{1} x^{3}+1.279 x^{2}-6.463 x+20.17\end{array}$ \\
\hline \multicolumn{2}{|c|}{ Network configuration: Bus-Section "OPEN" (Equations for 33kV) } \\
\hline Voltage/Fault Current & Derived Equations \\
\hline Remaining Voltage (p.u) & $\begin{array}{l}-8.337 \times 10^{-6} x^{5}+1.942 \times 10^{-4} x^{4}-1.417 \times 10^{-} \\
3^{3}+7.319 \times 10^{-4} x^{2}+4.021 \times 10^{-2} x+ \\
0.7792\end{array}$ \\
\hline \multicolumn{2}{|c|}{ Network congiguration: Bus-Section “CLOSE” (Equations for $33 \mathrm{kV}$ ) } \\
\hline Remaining Voltage (p.u) & $\begin{array}{l}-2.994 \times 10^{-6} x^{5}-1.741 \times 10^{-5} x^{4}+1.806 \times 10^{-} \\
{ }^{3} x^{3}-2.329 \times 10^{-2} x^{2}+1.303 \times 10^{-1} x+0.6360\end{array}$ \\
\hline
\end{tabular}

\section{RESULTS AND DISCUSSION}

\section{A. Validation of simulation with calculation}

The accuracy of formulation based on simulation is being validated by comparing the values from simulation with calculation using equation (1) for 3-phase fault as shown in Table 6 for remaining voltage (Case I - Bus-section “CLOSE") [16][17].

TABLE VI

$\%$ DifFERENCE BETWEEN SiMULATION AND CALCULATION For REMAINING VolTAGE (CASE I - BUS-SECTION “CLOSE”)

\begin{tabular}{|c|c|c|c|}
\hline $\mathbf{d}(\mathbf{k m})$ & $\begin{array}{c}\text { Vsag (pu) 2Txs } \\
\text { (Simulation) }\end{array}$ & $\begin{array}{c}\text { Vsag (pu) 2Txs } \\
\text { (Calculation) }\end{array}$ & $\begin{array}{c}\text { Difference } \\
(\%)\end{array}$ \\
\hline 0.2 & 0.100 & 0.098 & $-2.04 \%$ \\
\hline 0.4 & 0.190 & 0.179 & $-6.15 \%$ \\
\hline 0.6 & 0.260 & 0.246 & $-5.69 \%$ \\
\hline 0.8 & 0.330 & 0.303 & $-8.91 \%$ \\
\hline 1.0 & 0.380 & 0.352 & $-7.95 \%$ \\
\hline 1.5 & 0.490 & 0.449 & $-9.05 \%$ \\
\hline 2.0 & 0.570 & 0.521 & $-9.40 \%$ \\
\hline 2.5 & 0.630 & 0.576 & $-9.38 \%$ \\
\hline 3.0 & 0.680 & 0.620 & $-9.68 \%$ \\
\hline 3.5 & 0.710 & 0.656 & $-8.23 \%$ \\
\hline 4.0 & 0.740 & 0.685 & $-8.03 \%$ \\
\hline 4.5 & 0.770 & 0.710 & $-8.45 \%$ \\
\hline 5.0 & 0.790 & 0.731 & $-8.07 \%$ \\
\hline 5.5 & 0.800 & 0.749 & $-6.81 \%$ \\
\hline 6.0 & 0.820 & 0.765 & $-7.19 \%$ \\
\hline 6.5 & 0.830 & 0.780 & $-6.41 \%$ \\
\hline 7.0 & 0.840 & 0.792 & $-6.06 \%$ \\
\hline 7.5 & 0.850 & 0.803 & $-5.84 \%$ \\
\hline 8.0 & 0.860 & 0.813 & $-5.78 \%$ \\
\hline 8.5 & 0.870 & 0.822 & $-5.84 \%$ \\
\hline 9 & 0.877 & 0.830 & $-5.66 \%$ \\
\hline
\end{tabular}

The percentage difference is marginal with highest being 9.68\%. The Root Mean Square Error (RMSE) calculated for 
remaining voltage formulation is $0.0461(4.61 \%)$, which is small.

\section{B. Validation of simulation with online measurement}

The result for $\%$ remaining voltage from simulation is being compare with voltage sag $(\% \mathrm{~V})$ from actual event captured by online measurement as shown in Table 7 .

TABLE VII

$\%$ DIFFERENCE BETWEEN FORMULA FROM SIMULATION AND ONLINE MEASUREMENT FOR REMAINING VOLTAGE (CASE I - BUS-SECTION "CLOSE")

\begin{tabular}{|c|c|c|c|c|c|}
\hline $\begin{array}{l}\text { Point of } \\
\text { common } \\
\text { coupling }\end{array}$ & $\begin{array}{l}\text { Date \& } \\
\text { time of } \\
\text { event }\end{array}$ & $\underset{(\mathbf{k m})}{\mathrm{d}}$ & $\begin{array}{c}\text { Vsag } \\
\text { (pu) } \\
\text { 2Txs } \\
\text { (Online } \\
\text { measure } \\
\text { ment) }\end{array}$ & $\begin{array}{c}\text { Vsag } \\
\text { (pu) } \\
\text { 2Txs } \\
\text { (formu } \\
\text { la) }\end{array}$ & $\begin{array}{c}\text { Differe } \\
\text { nce }\end{array}$ \\
\hline SMRK & $\begin{array}{l}\text { 29/11/14, } \\
\text { 03:55AM }\end{array}$ & 4.0 & 0.70 & 0.75 & -7.14 \\
\hline TKLG & $\begin{array}{l}\text { 17/01/16, } \\
\text { 10:50AM }\end{array}$ & 3.0 & 0.65 & 0.69 & -6.15 \\
\hline BBRU & $\begin{array}{l}02 / 08 / 16, \\
02: 55 \mathrm{PM}\end{array}$ & 1.5 & 0.46 & 0.50 & -8.69 \\
\hline RBDR & $\begin{array}{l}\text { 06/07/17, } \\
06.19 \mathrm{PM}\end{array}$ & 0.4 & 0.18 & 0.19 & -5.5 \\
\hline
\end{tabular}

The percentage difference is between $-5.5 \%$ and $-8.69 \%$ for fault distance between 0.4 to $4.0 \mathrm{~km}$. This showed that the formulation for characterization of voltage sag using fault simulation and regression analysis is fairly accurate.

\section{CONCLUSIONS}

The authors have formulated equations for deriving voltage sag characteristics for distribution system under two (2) different configurations $132 / 11 \mathrm{kV}$ and $132 / 33 / 11 \mathrm{kV}$ and two (2) operating condition i.e. bus-section "OPEN" and "CLOSE". The formulation is done using short circuit simulations of DIgSILENT Power Factory commercial software and regression analysis for two (2) types of impactful faults i.e. 3-phase and phase-to-phase faults.

The fast derivation method enables voltage sag characteristic to be made known to affected customers in areas without online monitoring. The characteristic of $\%$ remaining voltage and duration can be evaluate against standard like MS IEC 61000-4-34 (Class 3) to understand the immunity level of these customers. With this simplified and fast method, utility like TNB can not only meet the timeframe imposed by the regulator on PQ event reporting but also provides full detail on the voltage sag characteristic fairly accurately.

Further research is ongoing to extend the formulation for other distribution network configuration such as $132 / 33 \mathrm{kV}$ $2 \times 90$ MVA with $33 \mathrm{kV}$ cables of various lengths to $33 / 11 \mathrm{kV}$ 2x30 MVA substation.

\section{REFERENCES}

[1] S. Naderian and A. Salemnia, "Method for classification of PQ events based on discrete Gabor transform with FIR window and T2FK-based SVM and its experimental verification," IET Gener. Transm. Distrib., vol. 11, no. 1, pp. 133-141, 2017.

[2] L. E. Weldermariam, V. Cuk, J. F. . Cobben, and W. L. Kling, "The Influence of Critical Distance on Monitoring Dips in the MV Network," IEEE, 2014.

[3] M. F. Faisal and a. Mohamed, "Integrating the S-PQDA software tool in the utility power quality management system," 2011 IEEE Int. Electr. Mach. Drives Conf. IEMDC 2011, pp. 966-970, 2011.

[4] M. F. Faisal, A. Mohamed, and H. Shareef, "Prediction of incipient faults in underground power cables utilizing S-transform and support vector regression," Int. J. Electr. Eng. Informatics, vol. 4, no. 2, pp. 186-201, 2012.

[5] S. Khan, Industrial Power Systems. New York: CRC Press, 2008.

[6] W. N. W. Mahmood, R. N. Mukerjee, and V. K. Ramachandaramurthy, "Identification of voltage sag origin in a measurement deficient power network," Proceedings. Natl. Power Eng. Conf. 2003. PECon 2003., pp. 0-4, 2003.

[7] S. P. A. Karim, A. Asuhaimi, and M. Zin, "The Application of Fault Signature Analysis in Tenaga Nasional Berhad Malaysia," IEEE Trans. Power Deliv., vol. 22, no. 4, pp. 2047-2056, 2007.

[8] S. Kamble and C. Thorat, "Classification of voltage sags in distribution systems due to short circuit faults," Proc. Int. Conf. Optim. Electr. Electron. Equipment, OPTIM, pp. 257-264, 2012.

[9] M. Bollen, Understanding Power Quality Problems -voltage sags and interruptions. IEEE Press series on Power Engineering, 2000.

[10] M. H. J. Bollen, "Fast assessment methods for voltage sags in distribution systems," IEEE Trans. Ind. Appl., vol. 32, no. 6, pp. 1414-1423, 1996

[11] M. Bollen, "Method of critical distances for stochastic assessment of voltage sags," vol. 145 , no. $1,1998$.

[12] M. H. J. Bollen, "Additions to the method of critical distances for stochastic assessment of voltage sags," IEEE Power Eng. Soc. 1999 Winter Meet. (Cat. No.99CH36233), vol. 2, pp. 1241-1246, 1999.

[13] H. Saadat, Power System Analysis. McGraw Hill International Editions, 1999.

[14] M. H. J. Bollen, "Characterisation of voltage sags experienced by three-phase adjustable-speed drives," IEEE Trans. Power Deliv., vol. 12, no. 4, pp. 1666-1671, 1997.

[15] TNB, TNB Distribution Engineering Fundamentals, no. May. 2014.

[16] Amiruddin Ismail and Adel Ettaieb Elmloshi,"Logistic Regression Models to Forecast Travelling Behaviour in Tripoli City," International Journal on Advanced Science, Engineering and Information Technology, vol. 1, no. 6, pp. 618-623, 2011. [Online]. Available: http://dx.doi.org/10.18517/ijaseit.1.6.124.

[17] Moaath Shatnawi,Mohammad Faidzul Nasrudin and Shahnorbanun Sahran,"A new initialization technique in polar coordinates for Particle Swarm Optimization and Polar PSO," International Journal on Advanced Science, Engineering and Information Technology, vol. 7, no. 1, pp. 242-249, 2017. [Online]. Available: http://dx.doi.org/10.18517/ijaseit.7.1.1794.

[18] Suhaila Zainudin,Dalia Sami Jasim and Azuraliza Abu Bakar,"Comparative Analysis of Data Mining Techniques for Malaysian Rainfall Prediction," International Journal on Advanced Science, Engineering and Information Technology, vol. 6, no. 6, pp. 1148-1153, 2016. [Online]. Available: http://dx.doi.org/10.18517/ijaseit.6.6.1487. 